\title{
MÉTODO
}

FENOMENOLÓGICO

HERMENÉUTICO

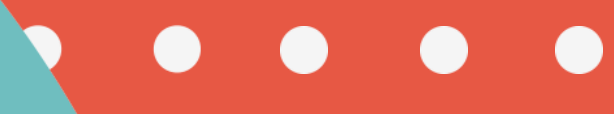

$0 \quad 0 \quad 0 \quad 0$

$0 \quad 0$

$0 \quad 0 \quad 0$

$\circ \quad 0$

$\circ \quad 0 \quad 0$

LAURA FERNANDA AMAYA JIMENEZ JUAN CAMILO DÁVILA GONZÁLEZ HEIDY VANESSA JARA GONZALEZ LA URAKATHERINE M URCIATORRES

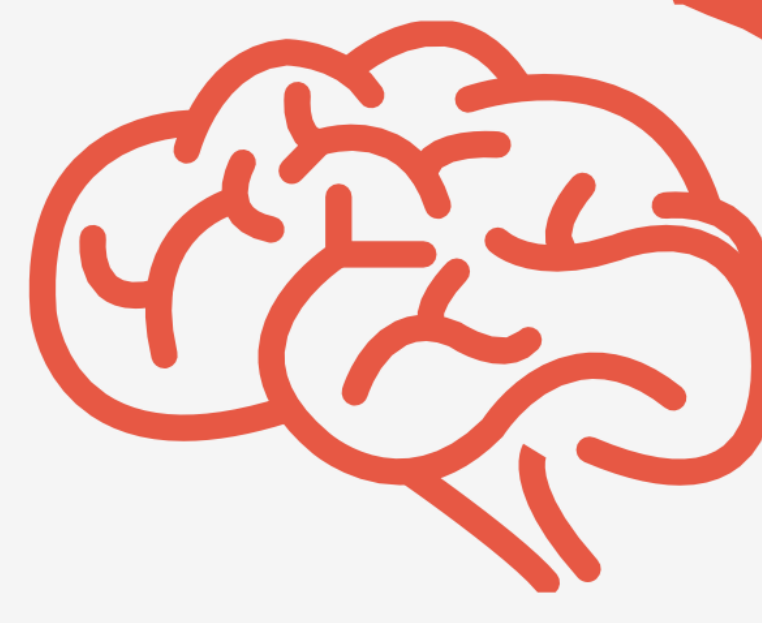

JULIE ALEJANDRA ROJAS SILVA 


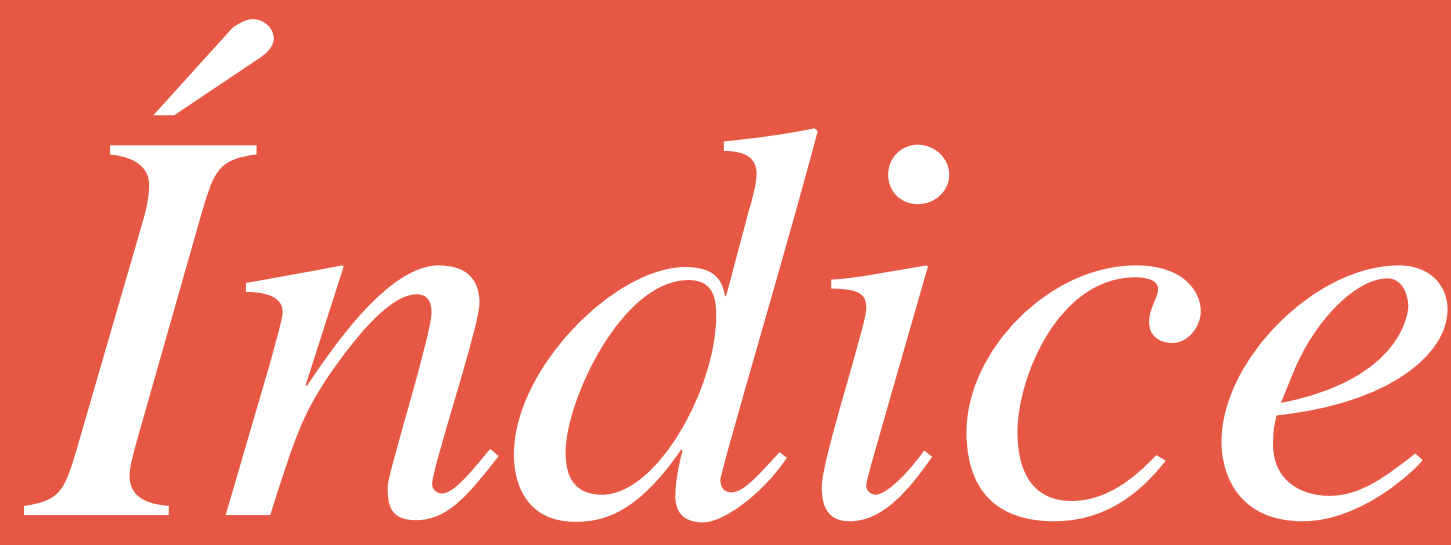

\section{MÉTODO \\ FENOMENOLÓGICO \\ HERMENÉUTICO}

¿Qué es y cómo surge?

02

Origen

03

Propósito

04

Características

08

Principios

Construcción del sentido frente al naturalismo científico 13

Fundamentación de la fenomenología y hermenéutica 15

La fenomenología hermenéutica como método 16

Fases del método fenomenológico hermenéutico. 


\section{¿Qué es y cómosurge?}

Dentro de la investigación cualitativa se encuentra el método fenomenológico el cual se fundamenta en el estudio de las

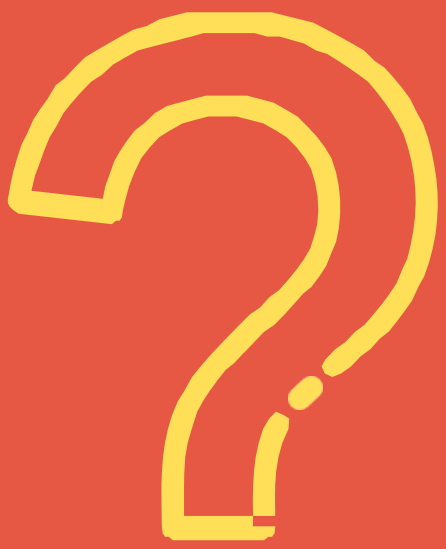
experiencias de vida, desde la perspectiva del sujeto, descubriendo así los elementos en común de tales vivencias.

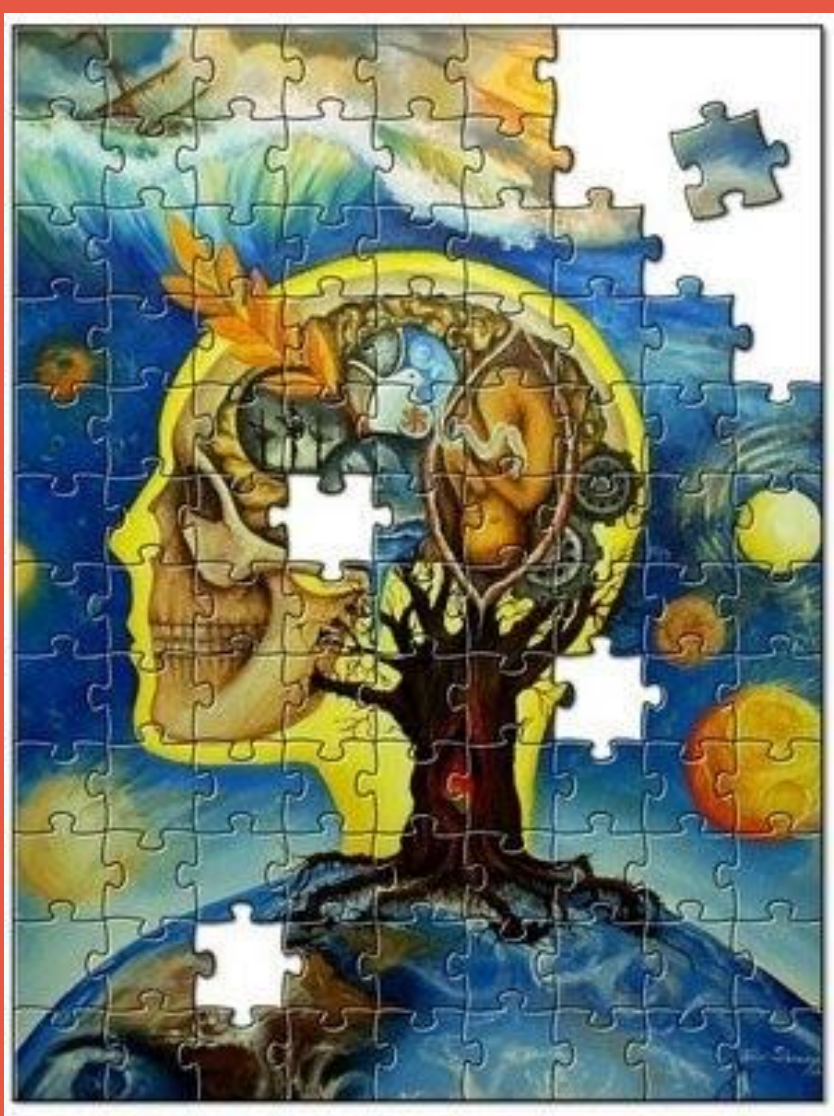

Recuperado de: (Google Imagen, 2020)

la 


\section{Origen}

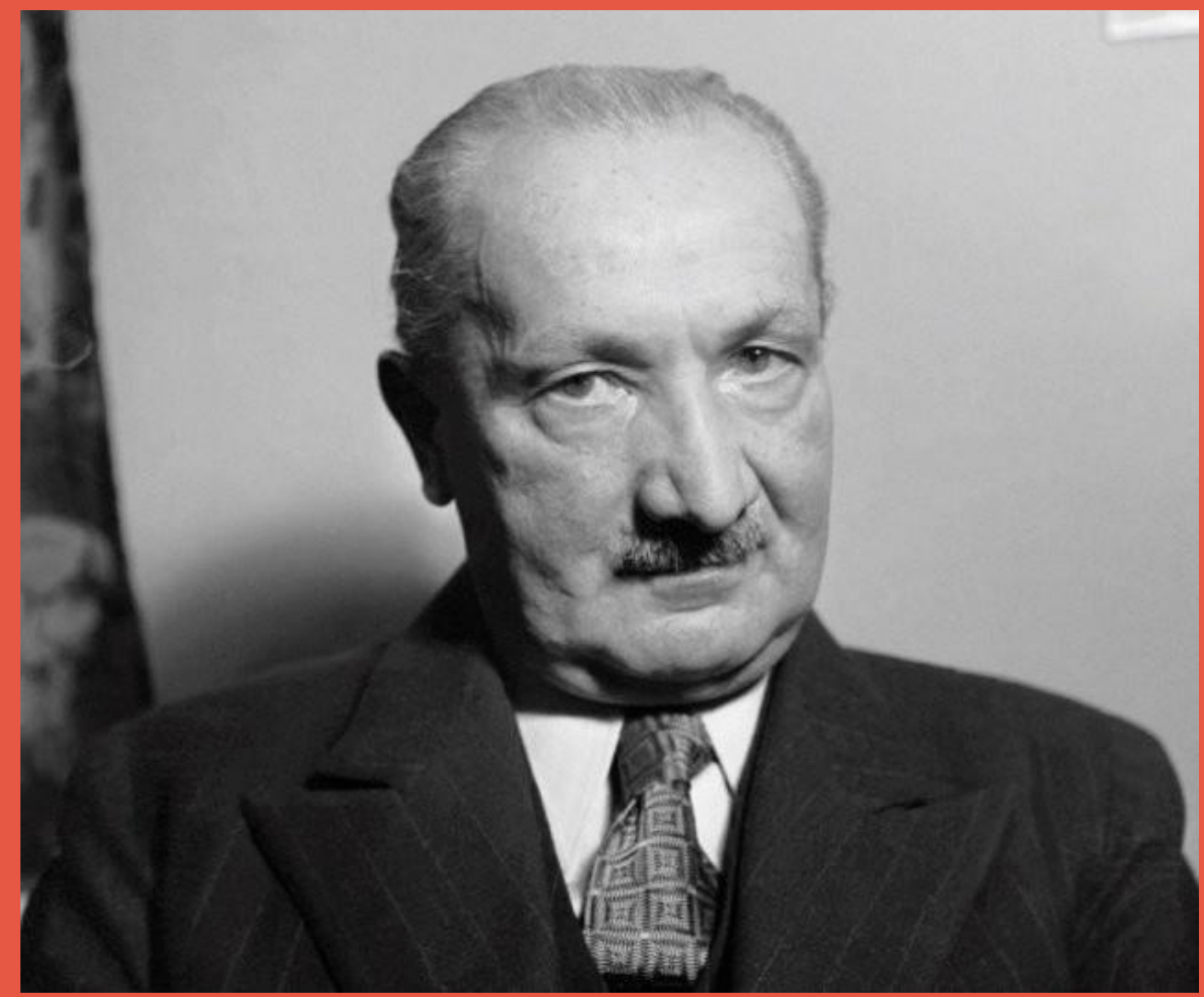

Recuperado de: (Google Imagen, 2020)

Heidegger (2006) sustentó que "la fenomenología pone énfasis en la ciencia de los fenómenos." Barberá e Inciarte (2012) apuntaron qué la fenomenología tiene sus orígenes en la palabra griega fenómeno que vendría a ser "mostrarse a sí misma, poner en la luz o manifestar que puede volverse visible en sí mismo" (p. 201) 


\section{Propósito}

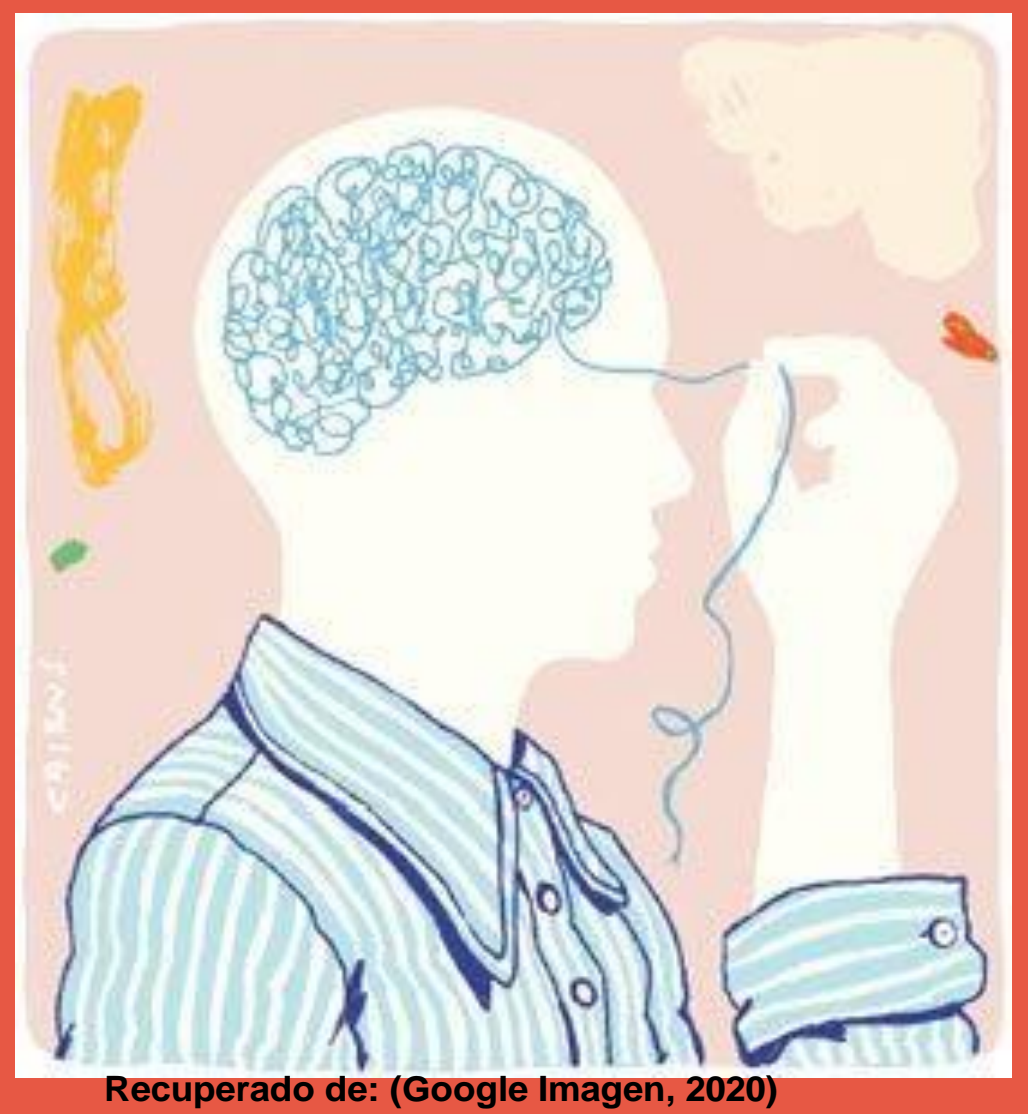

Diseños fenomenológicos:

Tanto

en

la

Su propósito principal es explorar, describir y comprender

las experiencias de las personas con respecto a un fenómeno y descubrir los elementos en común de tales vivencias.

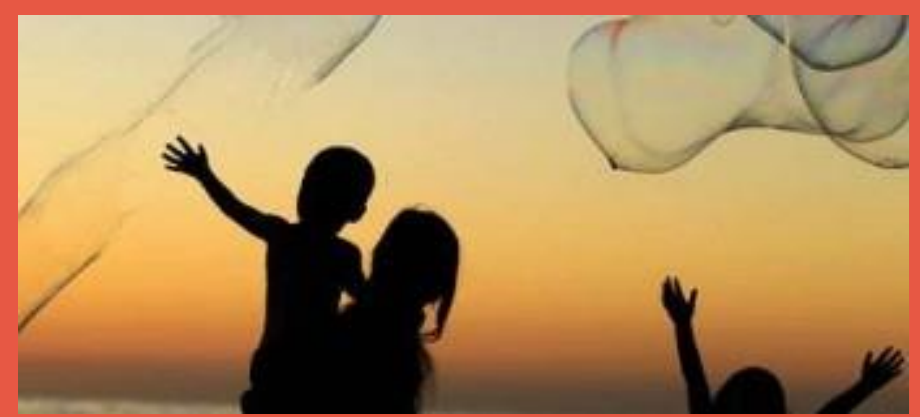

Recuperado de: (Google Imagen, 2020)

fenomenología como en la teoría fundamentada obtenemos

las perspectivas de los participantes.

Sin embargo, en lugar de generar un modelo a partir de ellas, se explora, describe y comprende lo que los individuos tienen en común de acuerdo con sus experiencias con un determinado fenómeno (categorías

que comparten en relación a éste) (Creswell, 2013) 
De esta manera, en la fenomenología los investigadores trabajan directamente las unidades o declaraciones de los participantes y sus vivencias.

El diseño fenomenológico se enfoca en la esencia de la experiencia compartida.

El fenómeno se identifica desde el planteamiento y puede ser tan variado como la amplia experiencia humana. Por ejemplo, una sensación individual interna, el cáncer de mama, el insomnio, el divorcio de los padres, el noviazgo, las preferencias por un determinado producto, trabajar con una nueva maquinaria, el incendio de una fábrica, un sistema educativo, una supernova, etc.

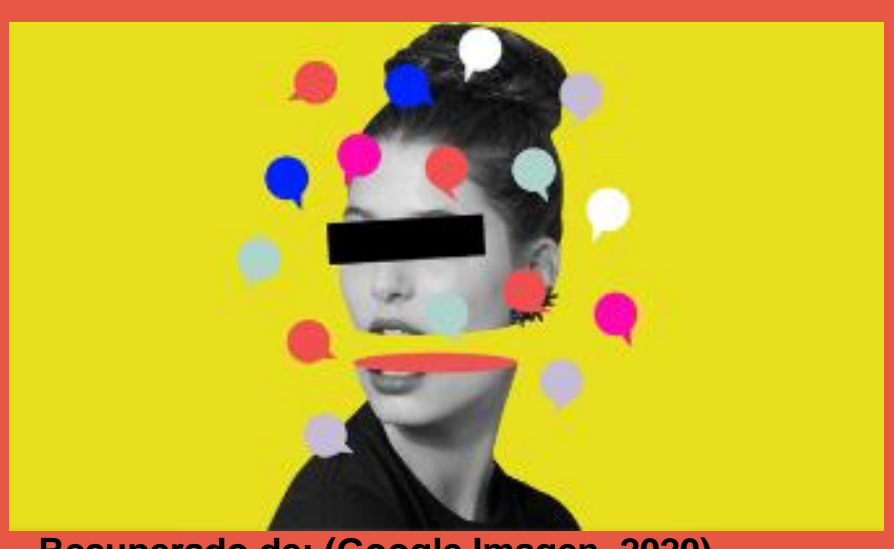

Recuperado de: (Google Imagen, 2020)
En ocasiones el objetivo específico es descubrir el significado de un fenómeno para varias personas. Una pregunta habitual de investigación de un estudio fenomenológico es la siguiente:

¿cuál es el significado. estructuray esencia de una experiencia vivida por una persona (individual), grupo (grupal) o comunidad (colectiva) respecto de un fenómeno? 
Primero, se identifica el fenómeno y luego se recopilan datos de las personas que lo han experimentado, para finalmente desarrollar una descripción

compartida de la esencia de la experiencia para todos los participantes lo que vivenciaron y de qué forma lo hicieron

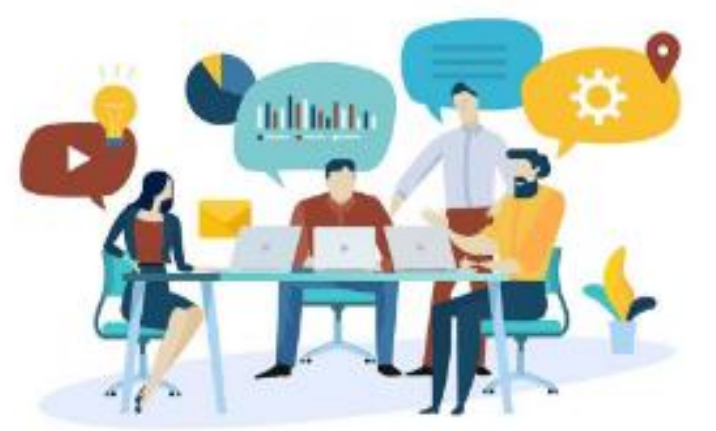

Recuperado de: (Google Imagen, 2020)

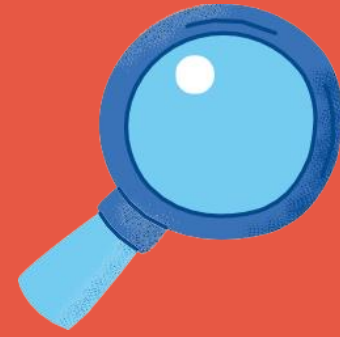

Recuperado de: (Canva, 2020)

Pueden utilizarse como herramientas de recolección de la información desde la observación (Creswell, 2013b) hasta entrevistas personales o grupos de enfoque, con preguntas abiertas,

semiestructuradas

estructuradas (Norlyk y Harder, 2010; y Heuer y Lausch, 2006), artefactos, documentos de todo tipo, grabaciones en audio y video

e incluso instrumentos

Herramientas que se pueden utilizar en los Diseños Fenomenológicos:

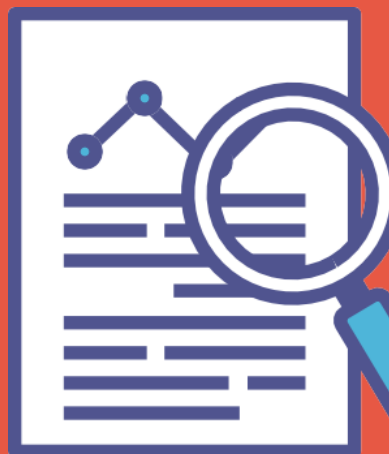

estandarizados.De acuerdo con Creswell (2013b), Mertens (2010) y Álvarez-Gayou (2003), el diseño fenomenológico se fundamenta en las siguientes premisas: 
- Se pretende describir y entender los fenómenos desde el punto de vista de cada participante y desde la perspectiva construida colectivamente.

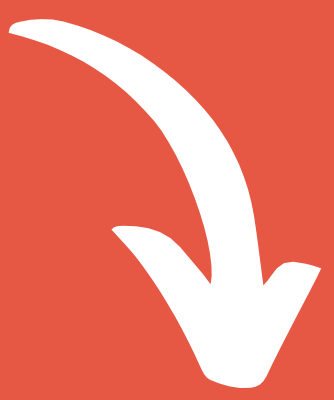

- Se basa en el análisis de

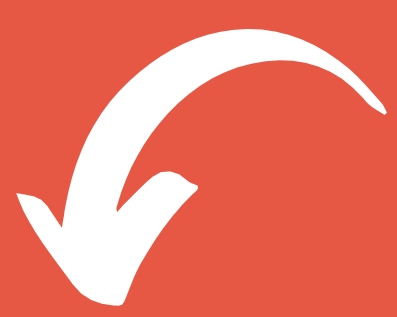
discursos y temas, así como en la búsqueda de sus posibles significados.

- El investigador confía en la intuición, imaginación y en las estructuras universales para lograr aprender la experiencia de los participantes.

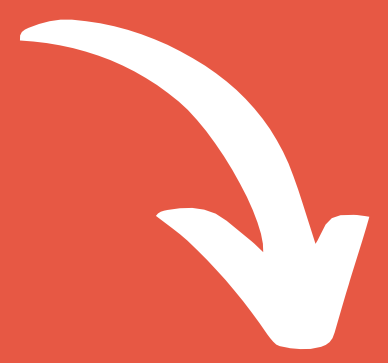

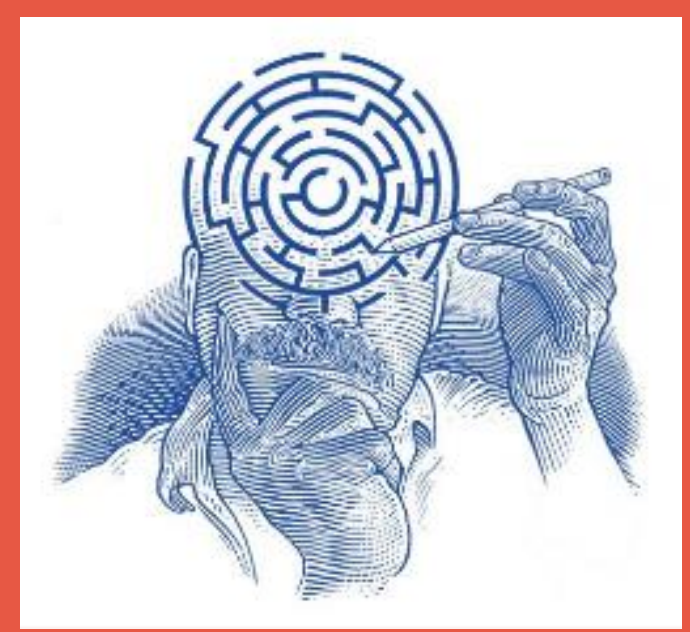

Recuperado de: (Google Imagen, 2020)
- El investigador contextualiza las experiencias en términos de su temporalidad (momento en que sucedieron), espacio (lugar en el cual ocurrieron), corporalidad (las personas que las vivieron) y el contexto relacional (los lazos que se generaron durante las experiencias). 


\section{Características}

El primer principio determinado por Husserl (citado en Villanueva, 2014) para aproximarse a la subjetividad, es la epojé o puesta entre paréntesis del supuesto de la actitud natural, presente en nuestro acercamiento habitual al mundo como en el propio quehacer de la ciencia: la asunción del Fuster, D. 204 Propósitos y Representaciones Ene.Abr. 2019, Vol. 7, $\mathrm{N}^{\circ} 1$ : pp. 201 - 229.

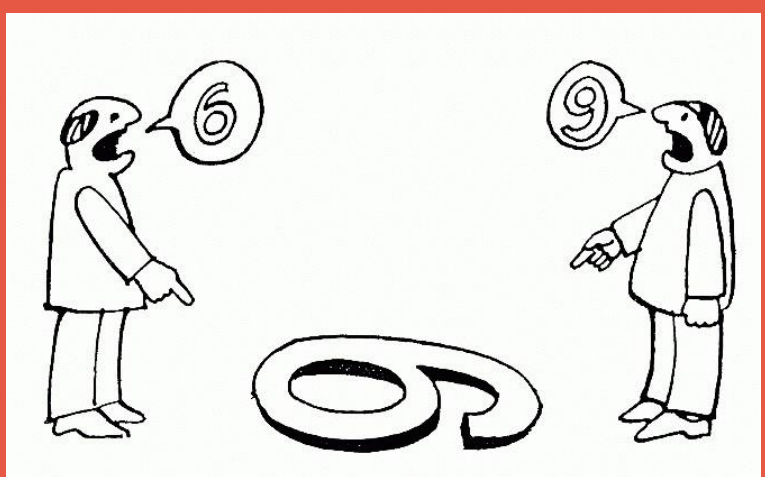

Recuperado de: (Google Imagen, 2020)

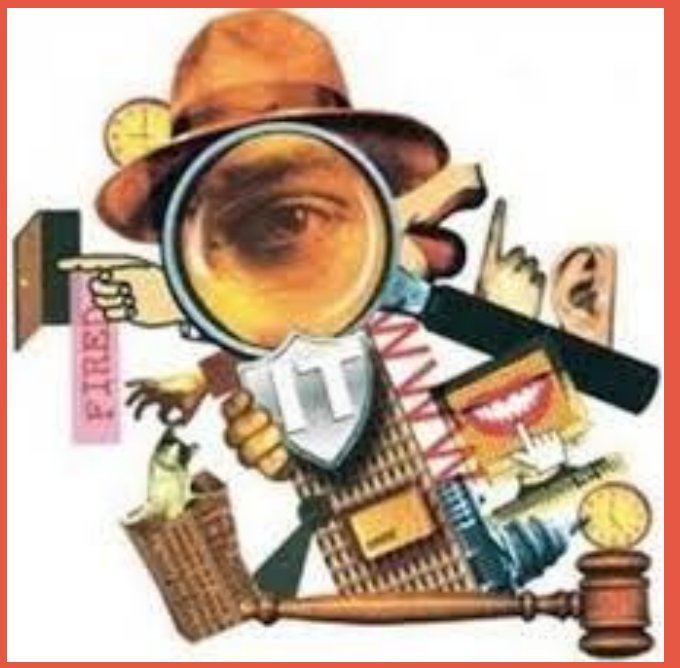

Recuperado de: (Google Imagen, 2020)

mundo como algo dado o de los hechos de este, como una realidad en sí misma, existente más allá de la conciencia que los piensa, valora o siente. En otras palabras, “la epojé hace referencia a la eliminación de todo lo que nos limita percibir las cosas mismas, ya que la actitud natural por su naturaleza objetiva nos lo impide. 
Practicar epojé, se refiere, abstenerse 0 prescindir" (Villanueva, 2014, p.220). Este principio no presume el cuestionamiento del mundo como existente ni reduce este al pensamiento del sujeto. Por lo contrario, trata de dejar de pensar bajo estos términos, con el objetivo de poder observar la vida de la conciencia que está detrás de los objetos comprendidos como cosas dadas: abordar cómo esta los representa, qué significado asume para ella.
A pesar de ello, se puede aseverar que su figura esencial es otorgar una condición para un nuevo conocimiento, suspender la condición natural.

$$
\text { Se }
$$$$
\text { admite }
$$

percibir el mundo y sus objetos como fragmento de la experiencia de una conciencia que les da un sentido. Implica estar advertido de una tendencia de la conciencia al ver el mundo como ya constituido y de olvidar su propia actividad, de convertirla en anónima.

En resumen, qué sentido original poseen o cómo se convierten en objetos de conciencia.De acuerdo con San Martín (1986), se precisan diferentes tipos de epojé en el

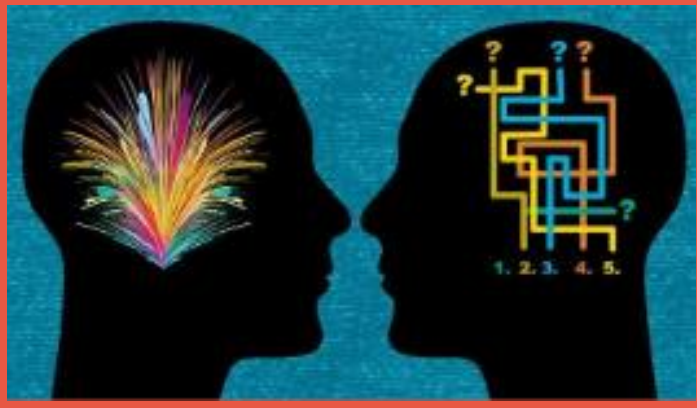

Recuperado de: (Google Imagen, 2020) desarrollo del análisis fenomenológico. 
La fenomenología surge como un análisis de los fenómenos

o

la experiencia significativa que se le muestra (phainomenon)

a la conciencia. Se aleja del conocimiento del objeto en sí mismo desligado de una experiencia. Para este enfoque, lo primordial es comprender que el fenómeno es parte de un todo significativo y no hay posibilidad de analizarlo sin el abordaje holístico en relación con la experiencia de la que forma parte.

Villanueva (2012) sostuvo que "la reducción fenomenológica es otro proceso céntrico del método fenomenológico" (p.48). Este presenta diferentes definiciones según Husserl.
La reducción se centra en percibir y describir las peculiaridades de la experiencia de la conciencia y comprender de modo sistemático cómo este mundo subjetivo está constituido. Este proceso de conocimiento demanda tanto la descripción como interpretación analítica. EI objetivo primordial es reconstruir los ejes articuladores de la vida de la conciencia, pero esto únicamente se puede ejecutar profundizando en su experiencia. Exige, describir y comprender la experiencia desde su propia lógica de organización. 


\section{Principios}

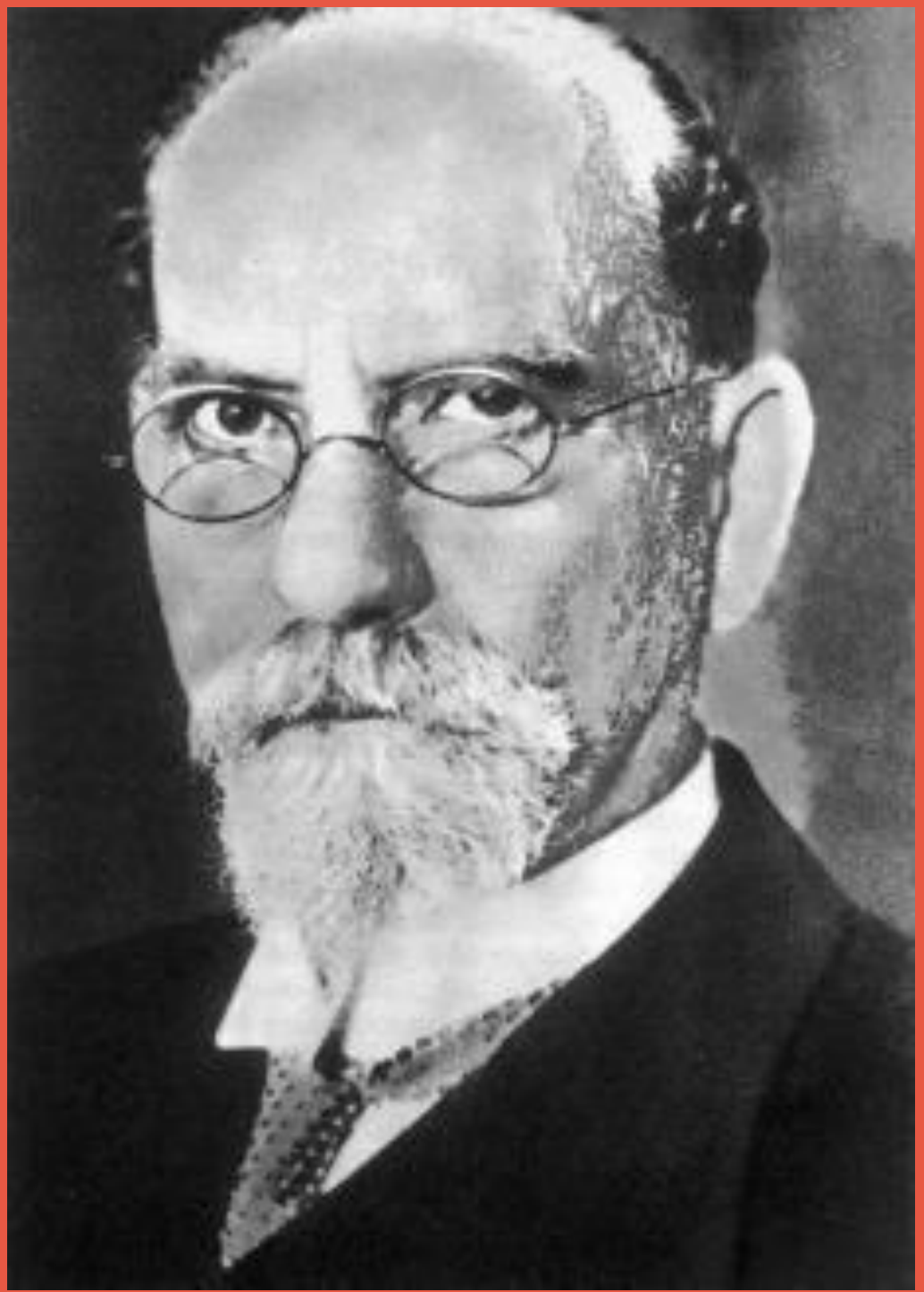

Recuperado de: (Google Imagen, 2020)

El primer principio determinado por Husserl (citado en Villanueva, 2014) para aproximarse a la subjetividad, es la epojé o puesta entre paréntesis del supuesto de la actitud natural, presente en nuestro acercamiento habitual al mundo como en el propio quehacer de la ciencia: la asunción del mundo como algo dado o de los hechos de este, como una realidad en sí misma, existente más allá de la conciencia que los piensa, valora o siente. 
Villanueva

(2012)

sostuvo

que

reducción

fenomenológica es otro

proceso céntrico del método

fenomenológico" (p.48).

Este

presenta

diferentes definiciones

según Husserl.

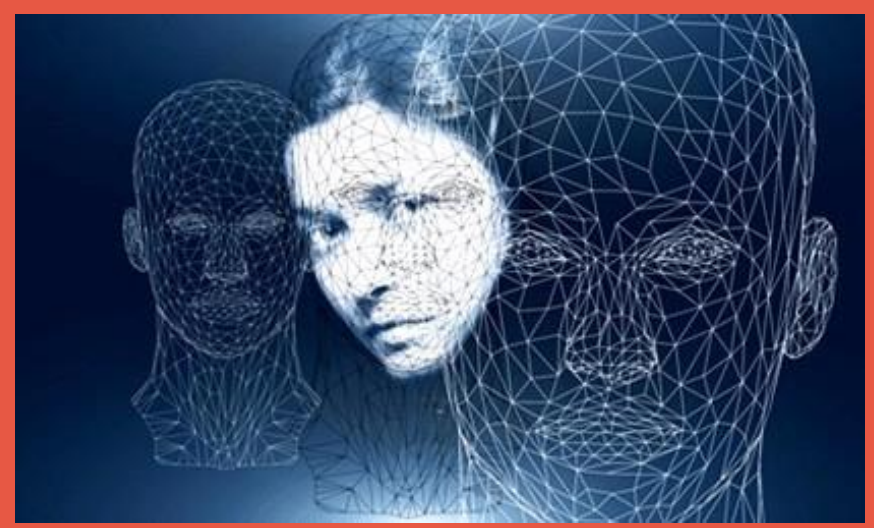

Recuperado de: (Google Imagen, 2020)

Exige, describir y comprender

la experiencia desde su propia lógica de organización.

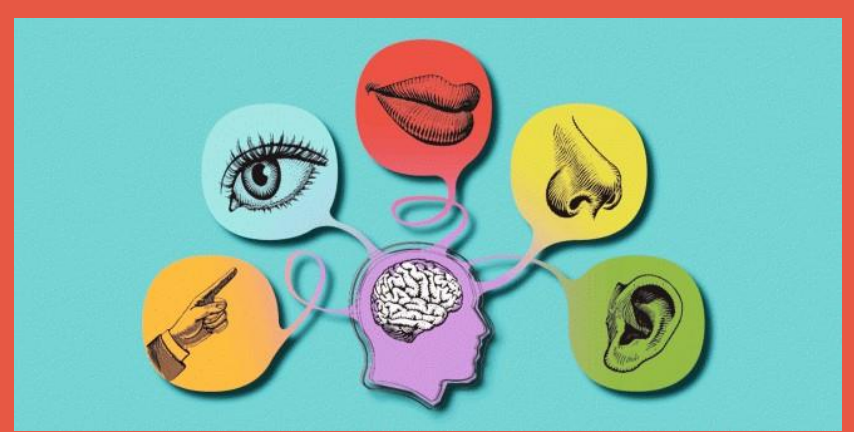

Recuperado de: (Google Imagen, 2020)

La reducción se centra en percibir y describir las peculiaridades de la experiencia de la conciencia y comprender de modo sistemático cómo este mundo subjetivo está constituido. Este proceso de conocimiento demanda tanto la descripción como interpretación analítica. EI objetivo primordial es reconstruir los ejes articuladores de la vida de la conciencia, pero esto únicamente se puede ejecutar profundizando en su experiencia. 


\section{Construcción del sentido frente al naturalismo \\ El enfoque}

fenomenológico proyecta una crítica radical frente al naturalismocientífico, el cual asume que el objeto de la ciencia es hallar leyes que gobiernan lo real, donde la persona es concebida como un objeto más de naturaleza.

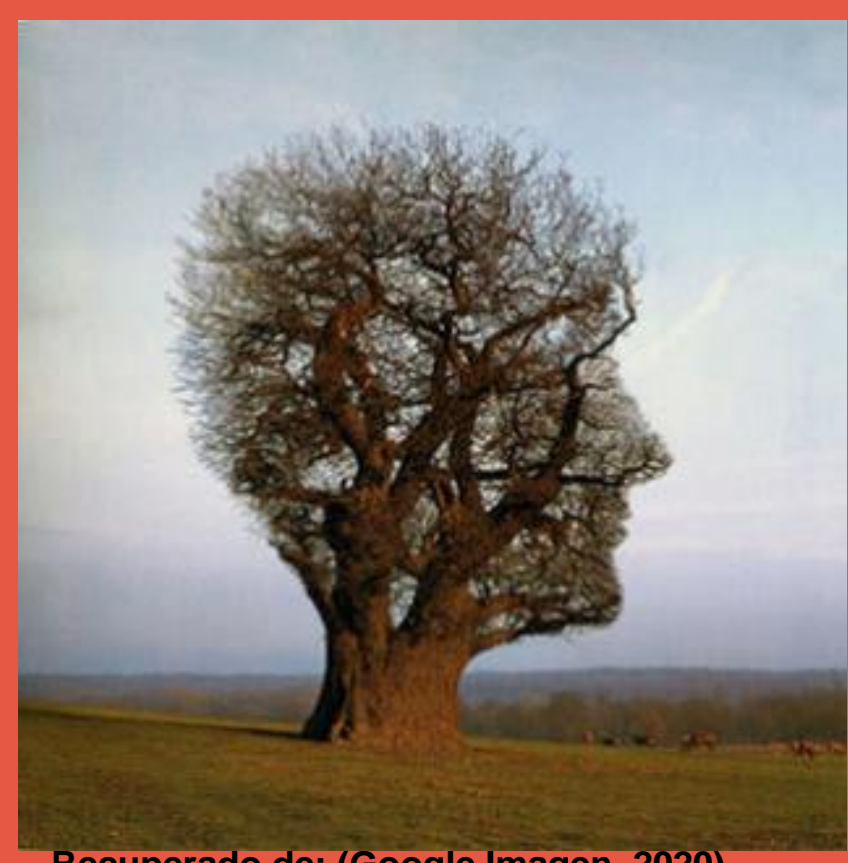

Recuperado de: (Google Imagen, 2020)
Recuperado de: (Canva, 2020)

La fenomenología expone que la conciencia, tratada como objeto,ofrece un límite a esta pretensión: la subjetividad humana es el fundamento de todo conocimiento científico. Por ende, existe un error lógico al tratar de exponer el fundamento a través de lo que este ha fundado. Entonces, se trata de entender qué nueva aproximación requiere la subjetividad para ser comprendida. 
EI naturalismo posee una postura objetivista de la ciencia, que concibe al objeto del conocimiento como producto apartado de la subjetividad. Es más, este paradigma de la ciencia pretende cualquier rasgo de subjetividad conocimiento.La fenomenología, por su parte, muestra que con ese accionar pierde el fundamento de su propio proceder.

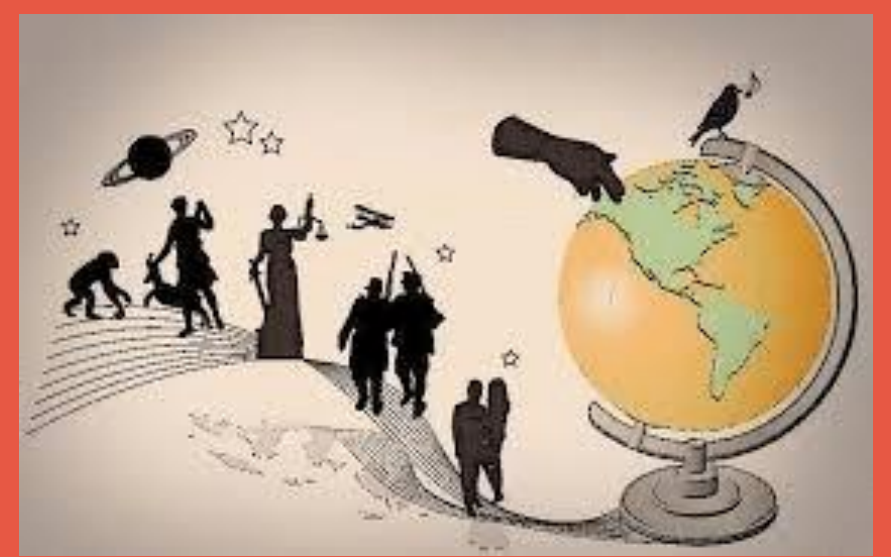

Recuperado de: (Google Imagen, 2020)
Por su parte, la fenomenología es entendida no únicamente como un ejercicio previo al quehacer científico, sino como una metodología que admitía una nueva modalidad de aproximarse al conocimiento y que facilitaba sus mejores frutos, aplicada a las ciencias humanas o la ciencias sociales. Como enfoque, se propone resolver las siguientes cuestiones: cómo estudiar esta subjetividad y cómo abordar la producción de sentido que le es inherente 


\section{Fundamentación de la}

fenomenología y hermenéutica

Para Husserl (1992), "la fenomenología otorga un nuevo método descriptivo y una ciencia apriorística que se desglosa de él y que está destinada a suministrar el órgano fundamental para una filosofía rigurosamente científica" (p.52).

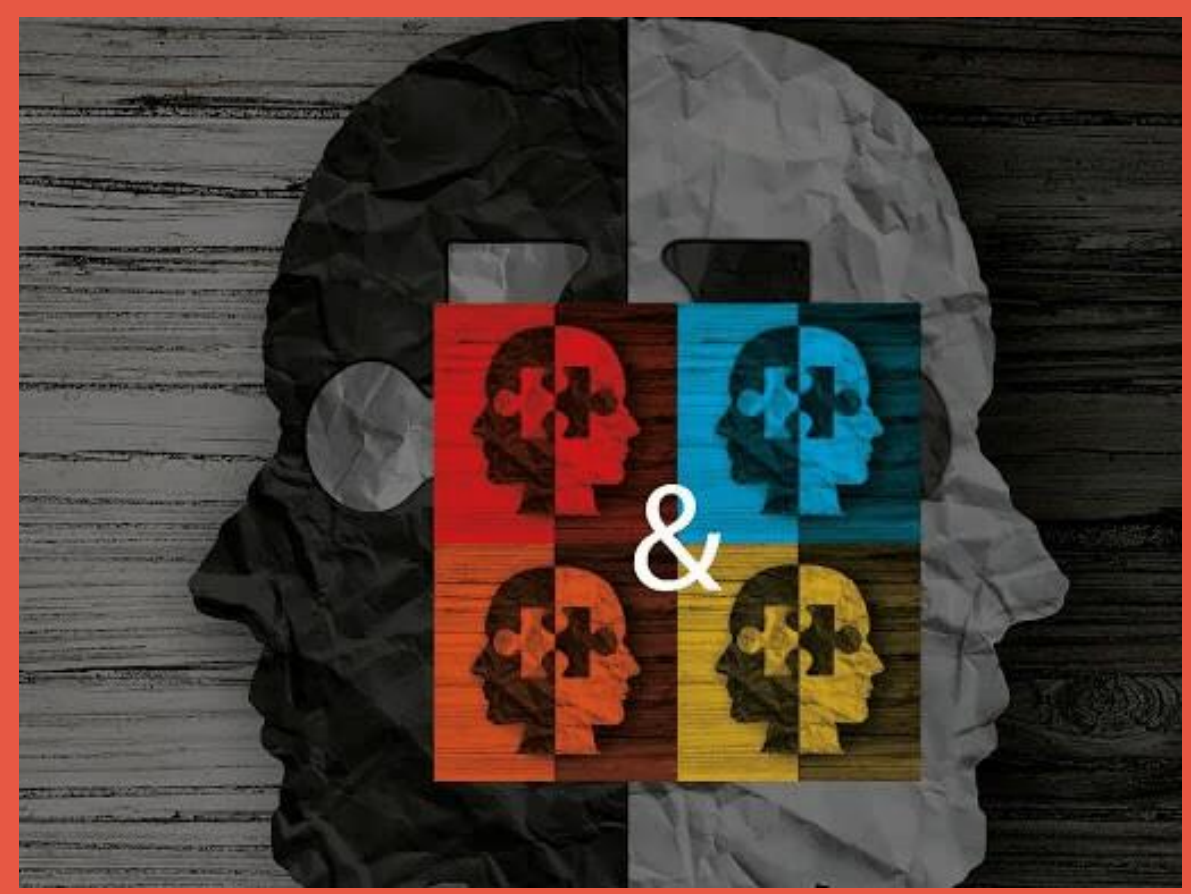

Recuperado de: (Google Imagen, 2020) 


\section{La fenomenología}

\section{hermenéutica como}

\section{método}

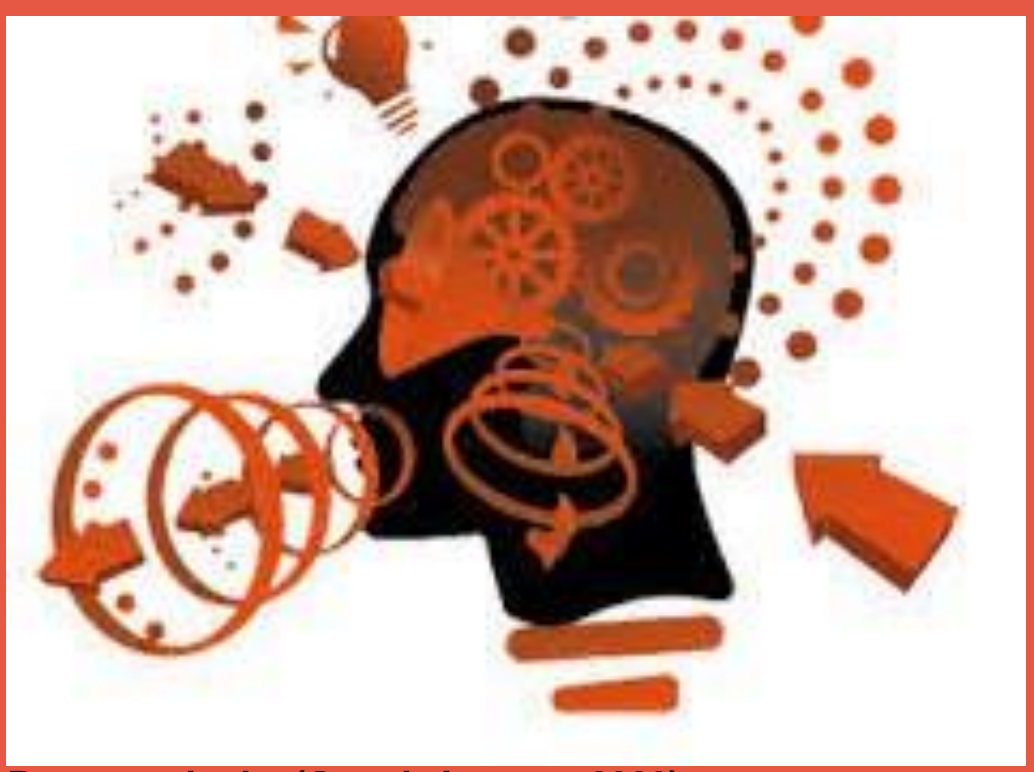

Recuperado de: (Google Imagen, 2020)

Este enfoque está orientado a la descripción e interpretación de las estructuras fundamentales de la experiencia vivida, al reconocimiento del significado del valor pedagógico de esta experiencia. Este método compone un acercamiento coherente y estricto al análisis de las dimensiones éticas, relacionales y prácticas propias de la pedagogía cotidiana, dificultosamente accesible, a través de los habituales enfoques de investigación. En esta contribución, se exhibe la potencialidad y aporte particular del método para la indagación educativa y se presentan ciertas nociones metodológicas y actividades básicas para la práctica investigativa. 


\section{Fases del método fenomenológico hermenéutico.}

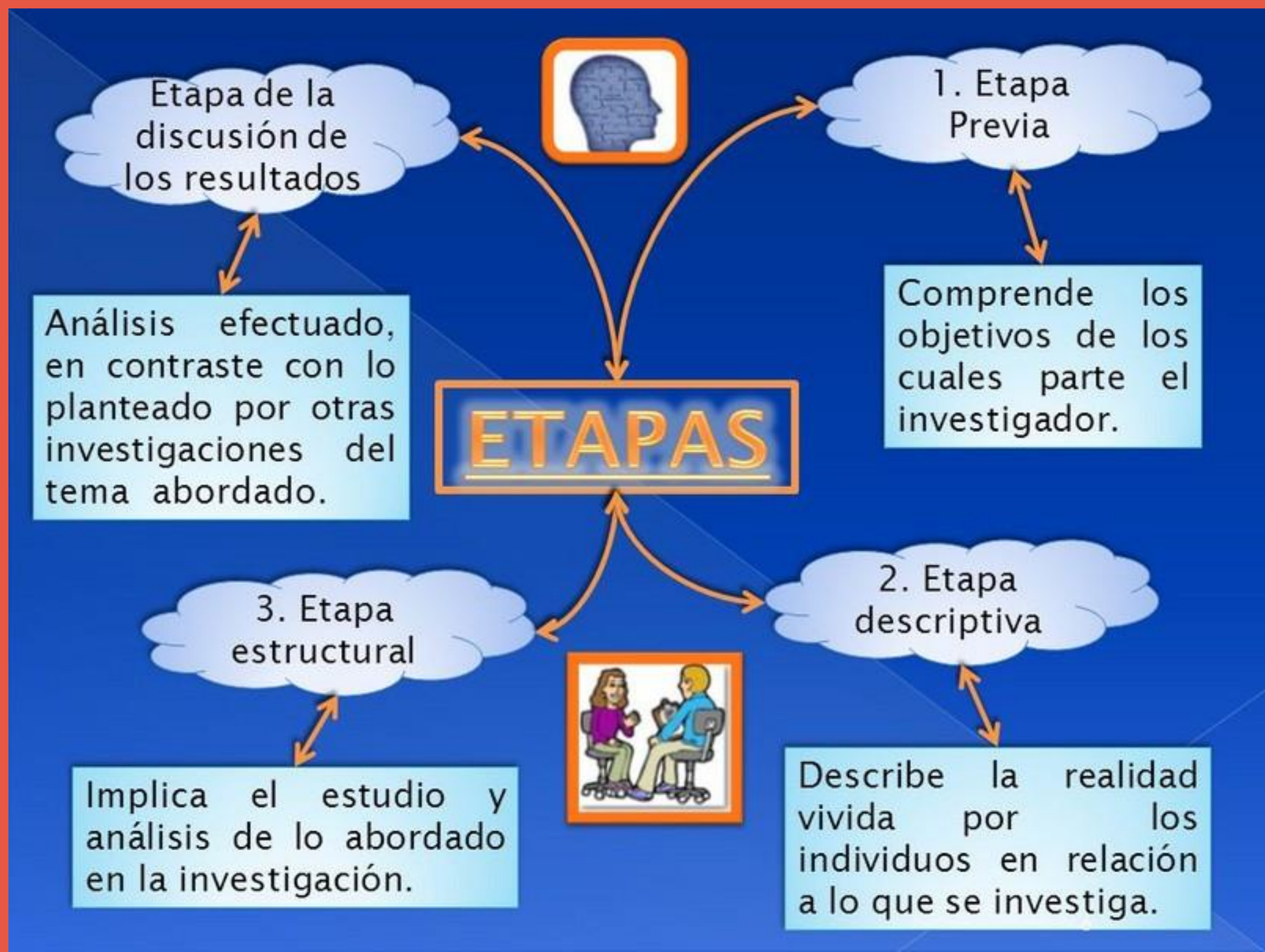

Recuperado de: (Google Imagen, 2020)

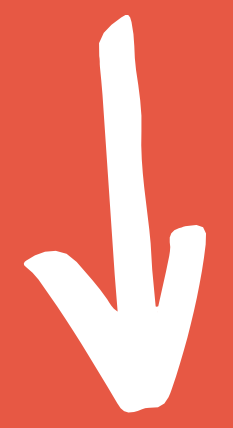




\section{Primera fase: Etapa previa o clarificación de presupuestos.}

La libertad de prejuicios de la que un investigador pueda sospechar será con considerable probabilidad,

contaminada por la tradición, religión, códigos éticos y la cultura misma que conforman el mundo preconcebido. A pesar de ello, el sociopedagogo deberá de liberarse de estos, para no afectar lo que, con buena voluntad, puede ser transparente. Admite al sociopedagogo ser aséptico y crítico.
El fenomenólogo no relega a los teóricos, pero prefiere prescindir de ellos para obtener la libertad de pensamiento.

Martínez

(2004)

hizo alusión al descenso de las teorías es una epogé metodológicamen te habilidosa, que se cumple en esta etapa. 
Se trata de establecer los presupuestos, hipótesis, preconceptos desde los cuales parte el investigador y reconocer que podrían intervenir sobre la investigación. Del mismo modo, son mostrados las concepciones teóricas sobre las cuales está estructurado el marco teórico que orienta la investigación, así como los sistemas referenciales, espaciotemporales sociológicos que tengan relación con los datos obtenidos del fenómeno en estudio.

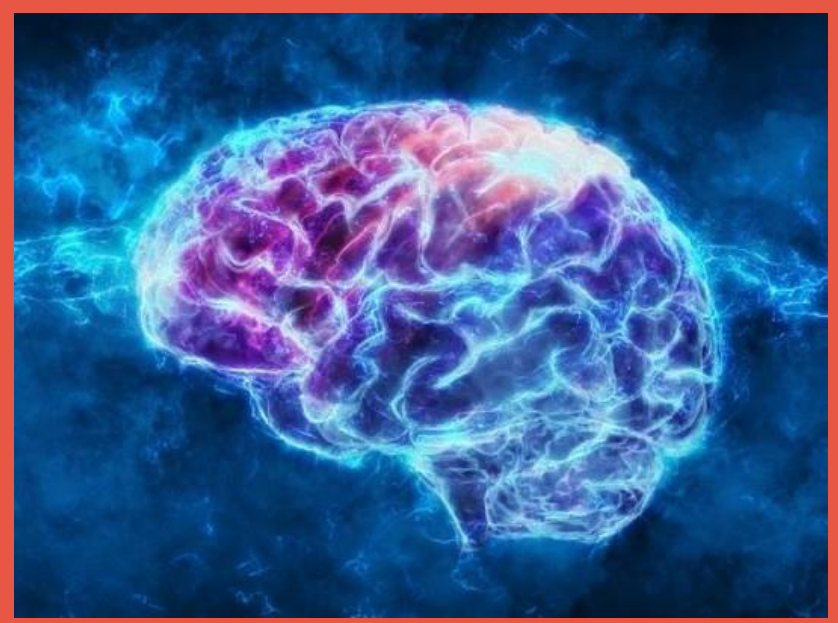

Recuperado de: (Google Imagen, 2020)

Ello se realizará por medio derespuestasa las cuestiones postuladas sobre nuestras actitudes, valores, creencias, presentimientos,

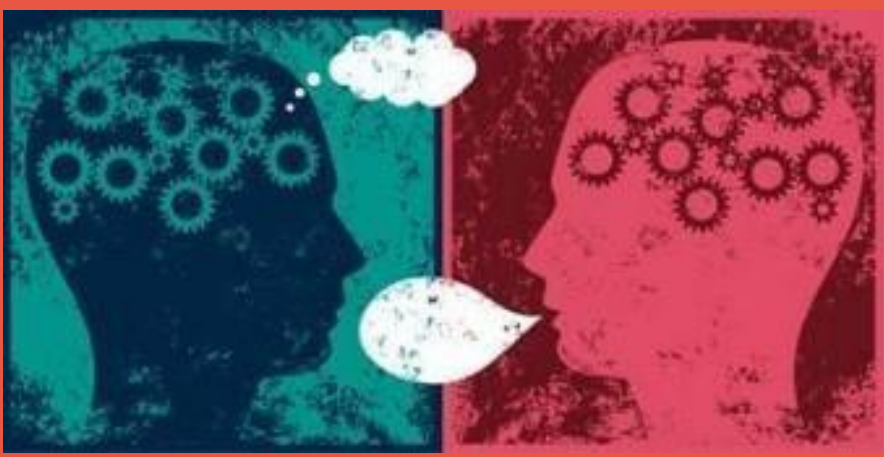

Recuperado de: (Google Imagen, 2020) conjeturas, interés, etc., en relación a la investigación con el objetivo de evitar la presencia de estas en la interpretación de las experiencias. 
Segunda fase: Recoger

la experiencia vivida.

Es la etapa descriptiva, pues aquí se obtienen datos de la experiencia vivida desde numerosas fuentes: relatos de la experiencia personal, protocolos de la experiencia de algunos docentes, entrevistas, relatos autobiográficos y observación- descripción de un documental. Se otorga apertura a la investigación con la escritura de anécdotas, una herramienta metodológica usual en FH.

También se puede aplicar en escenarios como la familia, pues como mencionan Rojas \& Perdomo (2019), ésta configura "el primer grupo al cual se afilian los individuos y se desarrollan, gracias a sus experiencias conjuntas, cosmovisión y valores que infieren en el proceso de socialización" (p.172).
Consideramos a Max Van Manen (2003) quien encomendó que "antes de solicitar a otros que nos brinden una descripción sobre un fenómeno a explorar, tendríamos que intentar hacer una primera nosotros, para poseer una percepción más puntual de lo que pretendemos obtener" (p. 82). 


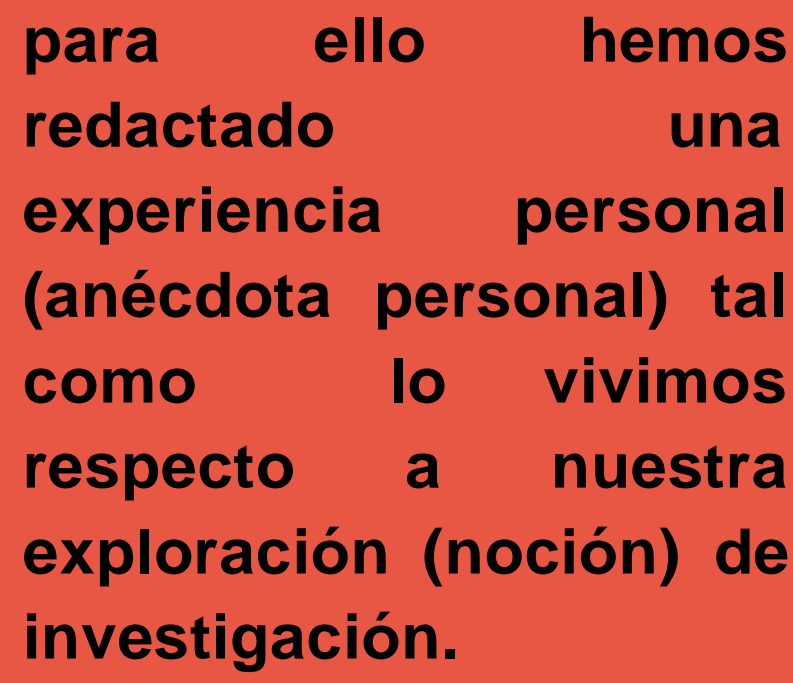

redactado

experiencia

personal (anécdota personal) tal como lo vivimos respecto a nuestra investigación.

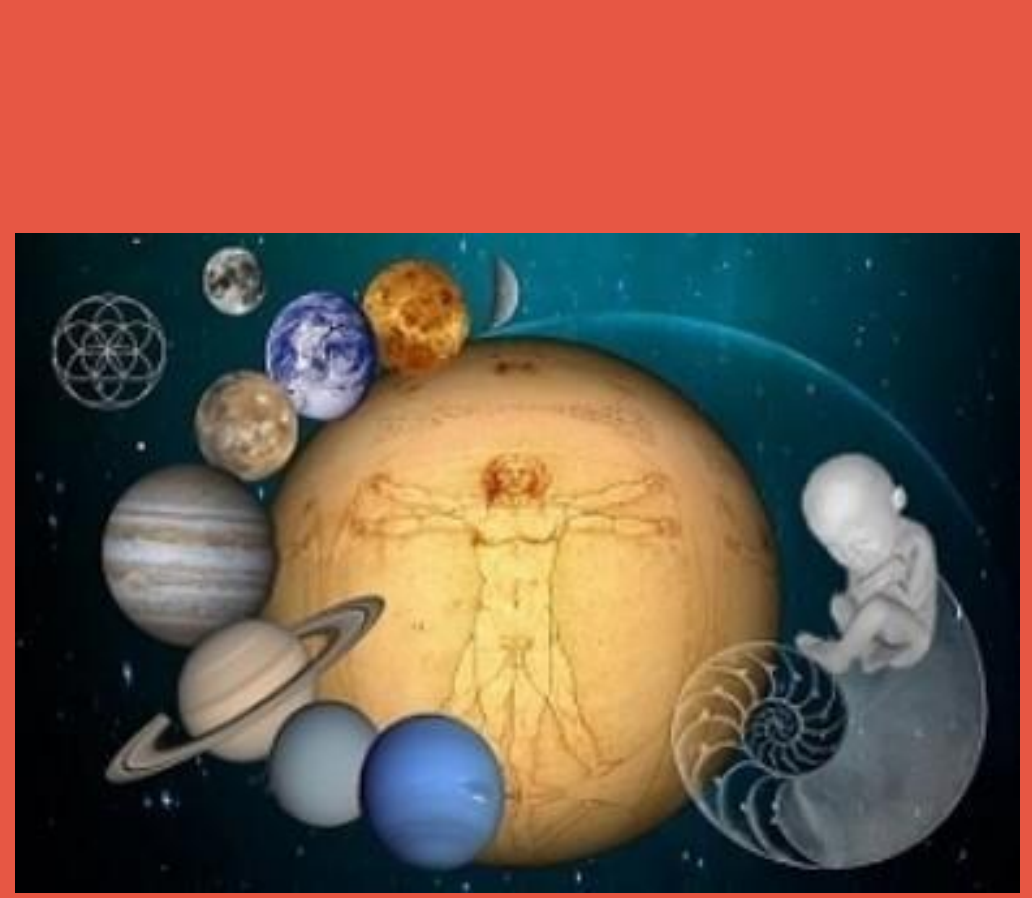

Recuperado de: (Google Imagen, 2020)

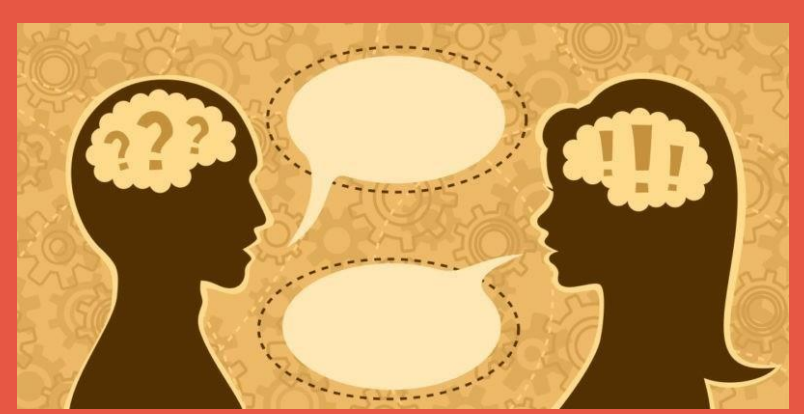

Recuperado de: (Google Imagen, 2020)

Según Van Manen (2003), "la anécdota simboliza a una de las herramientas con la cual se pone al descubierto los significados ocultos" (p. 132), por lo que se puede concebir como herramienta

metodológica en las ciencias humanas para comprender cierta noción que fácilmente se nos escapa. 
Tercera fase: Reflexionar acerca de la experiencia vivida- etapa estructural.

En esta fase, el propósito radica en intentar aprehender el significado esencial de algo. La reflexión fenomenológica
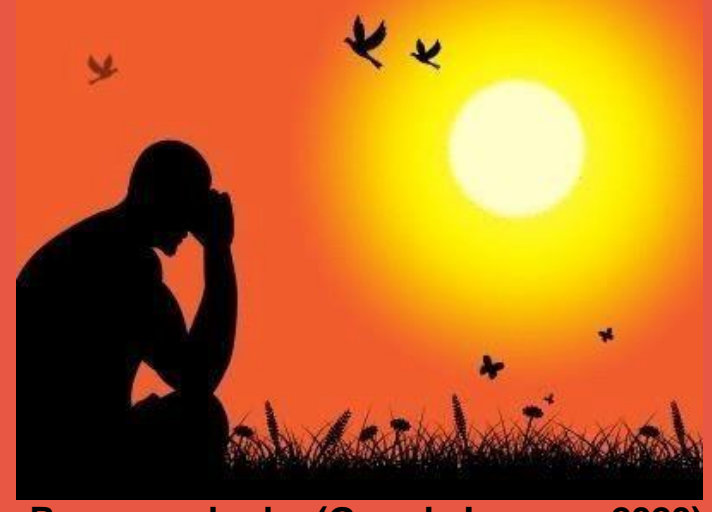

Recuperado de: (Google Imagen, 2020) es a la vez fácil y difícil. Es fácil debido a que examinar el significado o la esencia de un fenómeno es un proceso ejecutado constantemente en la vida cotidiana. Para Husserl (1980), cuando percibimos a un profesor, no solo observamos un hombre o una mujer. Vemos a un individuo diferente de los demás específicamente en ese aspecto que nos conlleva a hablar de él.

En otras palabras, yo, como el resto del mundo, tengo un concepto de profesor, pero lo que resulta complicado es llegar a una determinación y explicación reflexiva de lo que "es un professor". Según Max Van Manen (2003), esta búsqueda del significado es la tarea más dificultosa de la reflexión fenomenológica. 
En esta fase, se trata de efectuar un contacto más directo con la experiencia tal como se ha vivido. Se pretende captar el significado del hecho de ser profesor, madre o padre, para poder vivir mi vida pedagógica con los educandos de modo pleno. Por ende, cuando reflexiono sobre la experiencia de enseñar, no lo hago como psicólogo ni sociólogo, etc.

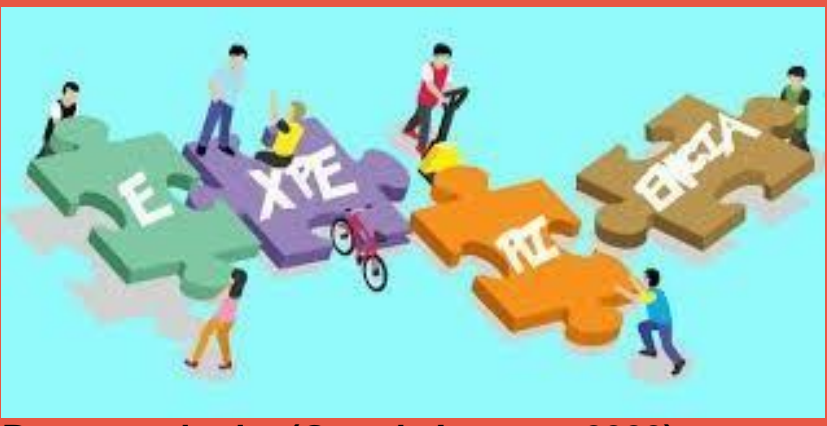

Recuperado de: (Google Imagen, 2020)

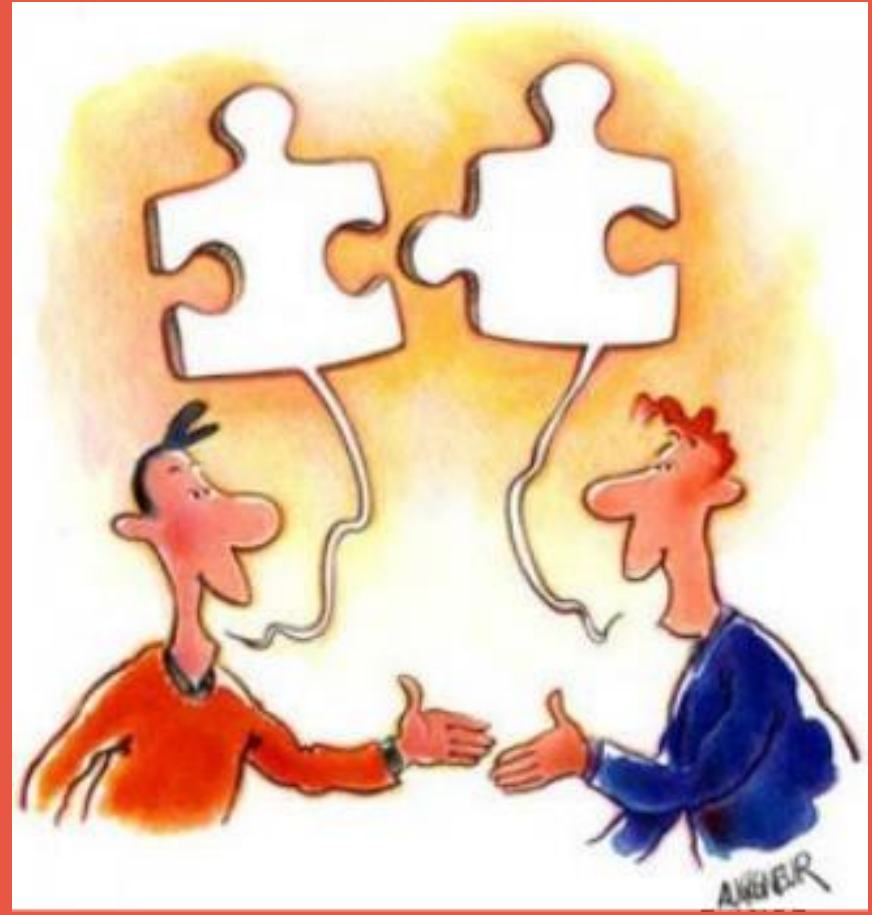

Recuperado de: (Google Imagen, 2020)

Por lo contrario, Van Manen (2003) enfatizó en la siguiente frase: "Reflexiono fenomenológicamente acerca de las experiencias de ser profesor o ser padre en tanto que profesor o padre. En resumen: intento captar la esencia pedagógica de una determinada experiencia" (p. 96). 


\section{Referencias}

○ Fuster Guillen, D. E. (2019). Investigación cualitativa: Método fenomenológico hermenéutico. Propósitos y Representaciones, 7(1), 201-229.

○ Ghiso, A. (1996). Métodos de la investigación cualitativa. Málaga. Ediciones Aljibe,39-59.

○Heidegger, M. (2006). Introducción a lafenomenología de la religión. México: Fondo de CulturaEconómica.

○HernándezSampieri,R.,FernándezCollado,C.,\&Baptista Lucio, P. (1996). Metodología de la Investigación. Bogotá: McGraw Hill.

`Inverso,H.G.(2018).¿Quéeslafenomenología? Lavía psicológicaylacolaboraciónentre Husserl y Heidegger en el artículo de la Enciclopedia Británica. Daimon Revista Internacional de Filosofía, (73), 181-198.

○ Leal, N. (2000). El método fenomenológico: principios, momentos y reducciones. Revista Electrónica de Investigación Científica, Humanística y Tecnológica, 1(5), 52-60.

- Moreno-Coutiño, A. B., \& Cuevas-Renaud, C. (2012). Análisis de aproximaciones metodológicas empleadas en el campo de la investigación en Psicología de la Salud. Revista Latinoamericana de Medicina Conductual/Latín American Journal of Behavioral Medicine, 2(1), 51-59.

-Rojas, J.A. y Perdomo, I.R. (2019). Experiencias de castigo físico en familias de la región de la Orinoquía colombiana. Revista Latinoamericana de Estudios de Familia, 11(2), 171-185. DOI: 10.17151/ rlef.2019.11.2.9.

○ Salgado Lévano, A. C. (2007). Investigación cualitativa: diseños, evaluación del rigor metodológico y retos. Liberabit, 13(13), 71-78 